\title{
IMÁGENES DE LUZ: APROXIMACIÓN A LA COLECCIÓN DE LITOFANÍAS DEL MUSEO NACIONAL DEL ROMANTICISMO
}

\author{
Isabel Ortega Fernández \\ Museo Nacional del Romanticismo, Madrid \\ isabel.ortega@mecd.es
}

\begin{abstract}
Este trabajo pretende ser una primera aproximación a las litofanías del Museo Nacional del Romanticismo, que conserva la colección pública más numerosa de Europa en lo que a estas piezas se refiere. Al hilo de las principales fábricas representadas en la colección que han podido identificarse hasta el momento, se abundará en las peculiares características de estos singulares y refinados objetos, particularmente en aspectos iconográficos, en sus diferentes formas y usos, y en los sistemas de marcaje e identificación de los modelos.
\end{abstract}

Palabras clave: Litofanías; Porcelana; Romanticismo; Iluminación

\section{LIGHT IMAGES: APPROACH TO THE COLLECTION OF LITHOPHANES IN THE MUSEO NACIONAL DEL ROMANTICISMO}

This article is a first approach to the study of the lithophanes in the Museo Nacional del Romanticismo in Madrid (Spain), the largest European public collection of these objects. The author traces the principal manufacturers represented in the collection thus far identified, and analyses the peculiar characteristics of these unique and refined objects. In particular, she examines aspects of their iconography, their different shapes and uses, as well as the stamps and marks that help identify the models.

Key words: Lithophanes; Porcelain; Romanticism; Illumination.

El Museo del Romanticismo conserva la colección pública de litofanías más numerosa de Europa y la segunda del mundo, a mucha distancia de la del Blair Museum of Lithophanes de Toledo (Ohio, Estados Unidos), que supera las dos mil trescientas piezas. El presente trabajo se centra fundamentalmente en las placas, que constituyen la gran mayoría de la colección. No obstante, también hay pantallas, lámparas, soportes, marcos y otros accesorios (fig. 1).

El término "litofanía" es un neologismo griego que significa "piedra translúcida", lo que podría inducir a error puesto que la materia básica no es la piedra sino la porcelana. Se trata en todo caso de placas o pantallas de gran refinamiento cuyas escenas en bajorrelieve hacían las delicias de las familias acomodadas en Europa y en Estados Unidos, a mediados del siglo XIX. Dispuestas en marcos, lámparas o veilleuses (calentadores de té) sobre las mesillas de noche y los tocadores de las alcobas, o bien suspendidas con cadenas o colgadores metálicos, o incluso incorporadas a la estructura de las ventanas de las distintas estancias, a modo de vidriera, decoraban los hogares de la burguesía decimonónica. Ese simple juego de colocar una luz y proyectar una imagen creando un efecto intimista y casi misterioso, muy acorde con el espíritu romántico, muestra la fascinación que durante el siglo XIX ejercieron los artilugios relacionados con la ilusión óptica, de los que las lito- 

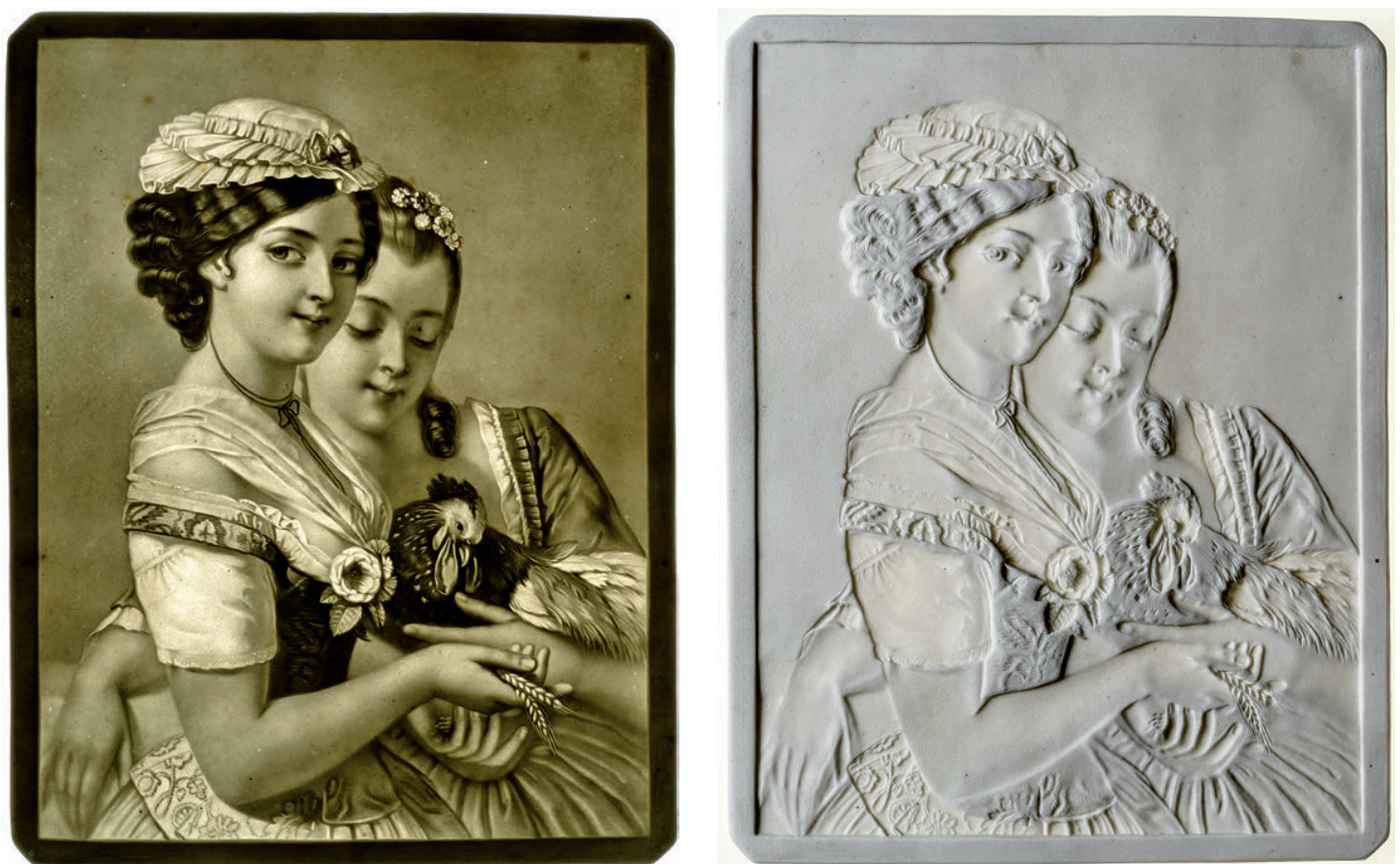

Fig. 1. Litofanía, Meissen Manufaktur, Zwei Mädchen mit Hahn, Museo del Romanticismo, Madrid. inv. CE8446. Fotografía: José Luis Huelves Morata.

fanías fueron precursoras en cierta forma. Nos referimos a la linterna mágica o al diorama como precedentes a su vez de la fotografía y el cine. Precisamente, los daguerrotipos y las fotografías llegaron a utilizarse con el tiempo como fuentes iconográficas de algunas placas ${ }^{1}$.

En contraposición a la popularidad que tuvieron en esa época, estos objetos son grandes desconocidos en la actualidad. De hecho, hasta hace muy poco ni siquiera aparecían definidos en el diccionario de la Real Academia de la Lengua. Ya en 1977, María del Pilar Arriola ${ }^{2}$ se hacía eco de esta circunstancia. No obstante, su vigésima tercera edición, de publicación reciente, incluye al fin una entrada conforme a la cual el término "litofanía" tiene dos acepciones:

1. Técnica decorativa que consiste en aumentar o disminuir el grosor de ciertos materiales translúcidos, como la porcelana, el alabastro o el vidrio opaco, para obtener efectos de mayor o menor luminosidad.

2. Objeto decorado mediante esta técnica.

Como expresan estas definiciones, reciben la denominación de "litofanía" tanto el objeto en sí como la técnica empleada para realizarlo. En este sentido, el primer modelo se grababa en una capa de cera previamente extendida sobre una plancha de cristal. La ductilidad de la cera permitía reparar los eventuales errores. Según Katherine Heugatter, "[1]a imagen habría tardado en completarse entre varias semanas y más de dos meses, dependiendo del tamaño de la pieza y de su complejidad"3. A partir de ese primer modelo se obtenía una matriz en yeso de la que, a su vez,

\footnotetext{
${ }^{1}$ Cook, 2014: 16.

2 Arriola, 1977: 26.

${ }^{3}$ Heugatter, 2010: 3.
} 
se sacaban subsiguientes moldes en los que se vertía la pasta de porcelana liberada de impurezas hasta su solidificación. A continuación, se retiraba y se colocaba en el horno para su cocción a elevadas temperaturas ${ }^{4}$. Como ha señalado Guisado Vázquez, "al necesitar varias cocciones y no poder controlar las hornadas tan cuidadosamente como hoy en día, muchas se arruinaban"5.

Con el uso repetido de los moldes, el resultado iba perdiendo calidad. Por otro lado, la cocción era más difícil de lograr cuanto mayor fuese el tamaño de las placas o cuanto más fino fuera el original de cera, aunque el resultado era aún más efectista, al filtrarse la luz con mayor intensidad a través de la porcelana. Por eso los productores de litofanías tenían una formación especial que les permitía desarrollar una gran habilidad para lograr las pequeñas diferencias en los relieves, que resultan en tonos más claros o más oscuros, devolviendo una imagen en grisalla cuyo efecto tonal, cuando es iluminada por el reverso, nos recuerda a una estampa. No en vano el arte de la litofanía podría ponerse en relación con el del grabador.

Como señala Margaret Carney, "[m]ientras que la inspiración para la creación de cuadros tridimensionales retro-iluminados hechos en porcelana sin duda vino de China, la inspiración para la escena de los más de 2.000 cuadros de porcelana tridimensionales diferentes provino de grabados, obras maestras y pinturas de género, historias bíblicas, escenas de Europa y América, y retratos de personajes en la historia, la literatura popular, la poesía y el teatro"6. En la colección del Museo del Romanticismo se dan todos estos supuestos, conservándose placas que reproducen obras de artistas nacidos en siglos precedentes como los antiguos maestros italianos Raffaello Sanzio (1483-1520) (Madonna della Sedia, inv. CE7808, y Madonna del Sixto, inv. CE7816 y CE7817) y Guido Reni (1575-1642) (Cristo coronato di spine, inv. CE7814), o como el holandés Caspar Netscher (1639-1684) (Die Spinnerin, inv. CE7789) y el francés Pierre-Paul Proud'hon (1758-1823) (L'Enlèvement de Psyché , inv. CE7726), pero también de pintores o grabadores franceses, ingleses y sobre todo alemanes nacidos ya en el siglo XIX como John Hayter (1800-1895) y William Henry Mote (1803-1871) (Ophelia, inv. CE1375), Theodore Hildebrandt (1804-1874) (Tankred und Klorinde, inv. CE1464), Wilhelm von Kaulbach (1804-1874) (The Guardian Angel, inv. CE7675, CE7676 y 7677), John Everett Millais (1829-1896) (My second sermon, inv. CE7671), Pierre Auguste Cot (1837-1883) (La tempête, inv. CE7711 y Le printemps, inv. CE7712), Heinrich Schlesinger (1814-1893) (Vergiss mein nicht!, inv. CE7723), Eduard Steinbrück (18021882) (Thisbe, inv. CE7725), Konstantin Johannes Franz Cretius (1814-1901) (Die Wahrsagerin, inv. CE7747), Meyer von Bremen (1813-1880) (Grossmutters Enkel, inv. CE7753, Erst beten, inv. CE7755 y CE7756, Drei Kinder nach dem Reißigholen, inv. CE7782 y CE7783, Großmutter und Enkelin stricken, inv. CE8377), William French (ca. 1815-1898) (Die neuen Hausgenossen, inv. CE7777), Jacob Becker (1810-1872) (Des Hauses und des feldes segen, inv. CE7784) o FrançoisClaudius Compte-Calix (1813-1880) (Gebet am Morgen, inv. CE7792). Vemos, por tanto, una prevalencia de fuentes iconográficas contemporáneas, existiendo en la época una especial predilección por el grupo de los Nazarenos.

Esta costosa técnica comenzó a desarrollarse a principios del siglo XIX en Francia y en Prusia. Siguiendo a Julia Sáez-Angulo, la primera porcelana transparente fue lograda en 1827 por el alemán Georg Friedrich Christoph Frick $^{8}$ (1781-1848), que llegó a dirigir la Manufactura Real de Berlín. Sea como fuere, lo cierto es que el 12 de enero de 1827 la patente francesa fue concedida al diplomático Paul Charles Amable de Bourgoing (1791-1864), que la explotó junto a su amigo

\footnotetext{
${ }^{4}$ Rather, Kirsten Dorothee/Przyborowski, Claudia/Stephan, Regina (2001): "Lithophanien: Die Welt des Biedermeier im Porzellanbild". En: http://www.gutshof-britz.de/ausstellungen/lithophanien/herstellung.htm [30-01-2015].

${ }^{5}$ Guisado, 1991: 13.

${ }^{6}$ Carney, 2008: 82.

${ }^{7}$ En la lista de precios de la Meissen Manufaktur figura el título "Venus in Wolken".

${ }^{8}$ Sáez-Angulo, 2008: 70.
} 


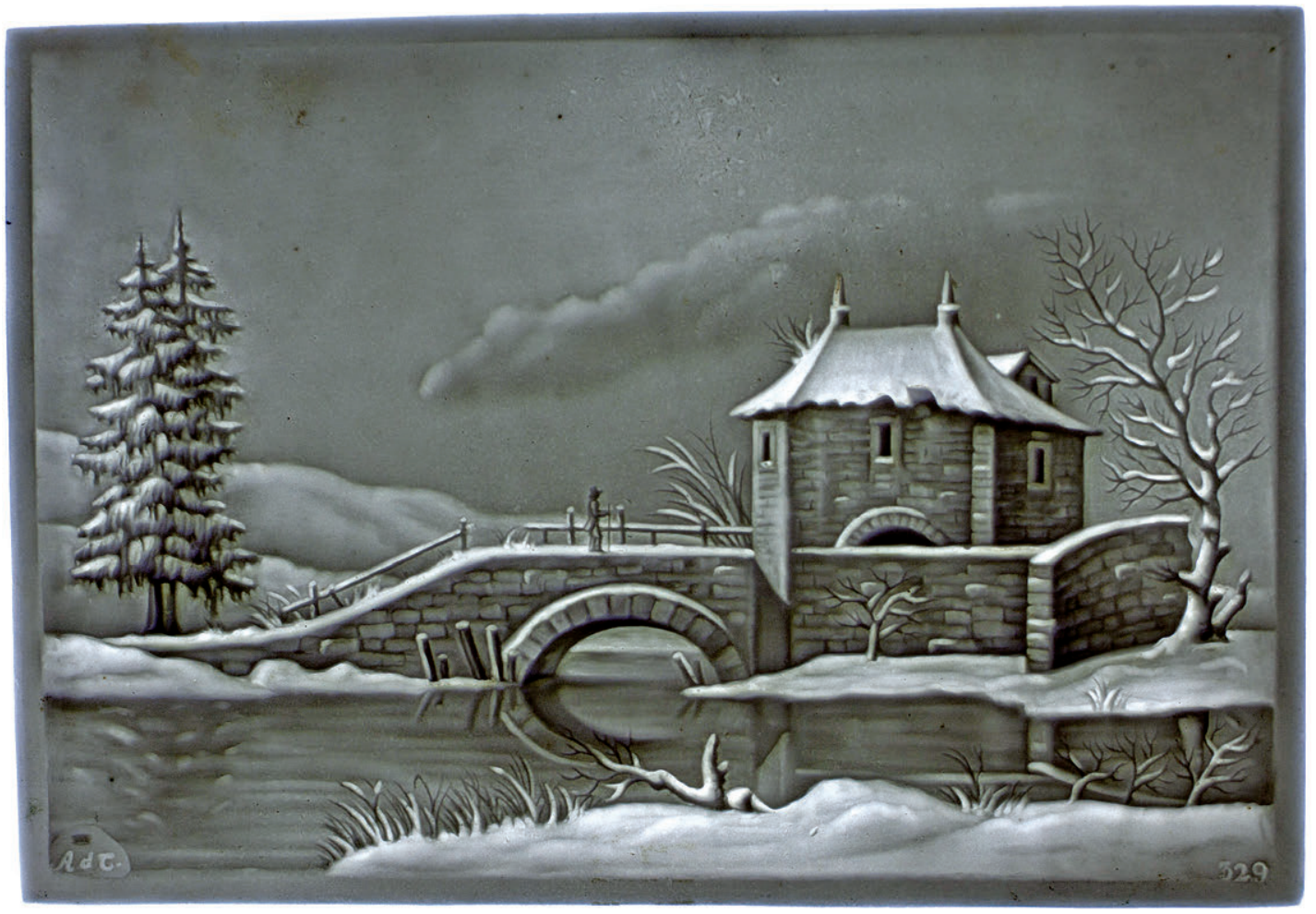

Fig. 2. Litofanía, Alexis du Tremblay, Museo del Romanticismo, Madrid. inv. CE7801. Fotografía: Víctor Gascón González.

Alexis Sylvain du Tremblay (1796-1869), con el que en octubre de ese mismo año creó una sociedad "para la explotación de un nuevo arte [...] llamado litofanía, proceso de degradación de las materias opacas por medio de la sombra y la luz"". Bourgoing no se equivocó puesto que Tremblay logró muy buenos resultados, como ejemplifica la única litofanía de esta procedencia que conserva el Museo del Romanticismo (inv. CE7801) (fig. 2). Se trata de una placa de gran belleza, con un paisaje invernal, que en el ángulo inferior izquierdo del anverso presenta la marca "AdT.", utilizada en su manufactura de Rubelles en el segundo cuarto del siglo XIX. El número de modelo podría identificarse con el que aparece en el ángulo inferior derecho del anverso como una peculiaridad puesto que, habitualmente, todas las manufacturas lo marcan en el reverso, que en este caso sólo se ha reservado para una "S" incisa que podría ser una marca de artífice.

Otros centros franceses que destacaron en la producción de litofanías fueron Sèvres y Limoges. Hasta el momento no hemos podido atribuir tales procedencias a ninguna litofanía de la colección del Museo del Romanticismo. En Inglaterra, donde también las produjeron varias manufacturas ${ }^{10}$, "el procedimiento para realizar litofanías fue patentado (...) por Robert Griffith Jones el 13 de

${ }^{9}$ Minutes du notaire Antoine Simon HAILIG, 1827 octobre - 1827 décembre, Archives Nationales, Fontainebleau - Paris - Pierrefitte-sur-Seine, MC/ET/XXXV/1090. En: https://www.siv.archives-nationales.culture.gouv.fr/siv/rechercheconsultation/consultation/ir/consultationIR.action?udId=c1p6yurkzgln—8yfu6i5p1ivi\&consIr=\&irId=FRAN_IR_041953\&fron$\mathrm{tIr}=\&$ auSeinIR $=$ false [30-01-2015].

${ }^{10}$ Carney, 2008: 49-58.

${ }^{11}$ Cook, 2014: 16. 
marzo de 1828; al parecer, obtuvo la licencia de Bourgoing"11. También dedicaron una parcela de su actividad a estos objetos algunas manufacturas de Bélgica, Austria, Dinamarca o Noruega, entre otros países europeos. Sin embargo, fue sobre todo en Alemania donde se desarrolló la producción de litofanías y de donde proceden las de mejor calidad. De hecho, la mayoría de las que han llegado hasta nosotros son alemanas. A título de ejemplo, de las ciento treinta y ocho placas que integran la colección del Museo del Romanticismo en la actualidad, por el momento no hemos identificado ninguna inglesa. Por el contrario, más de cien de ellas son alemanas, estando representadas las tres manufacturas que despuntaron en la época. Así, más de un ochenta por ciento de ese centenar procede de la Plauesche Porzellanmanufactur o Porzellanmanufactur Plaue (PPM), fundada en 1817 por la familia von Schierholz en Plaue-am-Havel (Turingia), pero también hemos identificado ocho de la Manufactura Real de Meissen (Sajonia) y tres de la Manufactura Real de Berlín (Königliche Porzellan Manufaktur). Adicionalmente, están representadas otras fábricas alemanas que, aunque no destacaron como las anteriores, también tuvieron su cuota de mercado. Es el caso de Carl Heyroth \& Co. (Magdeburg-Sudenburg), de la que se conservan tres ejemplares, y de la Nymphenburg Porzellan Manufaktur (Munich), de la que hemos identificado dos placas.

\section{Plauesche Porzellanmanufactur (PPM)}

Aunque esta manufactura se fundó en 1817, en realidad se dio a conocer en 1849 gracias a las litofanías, cuya idea surgió de Gottfried Henklein. Según Margaret Carney, "en 1875 tenían ya una enorme cantidad de motivos y características imágenes populares en diferentes tamaños y formas" 12 . De hecho, produjo aproximadamente dos mil modelos durante su larga historia, más del doble que la Königliche Porzellan Manufaktur, de la que fue su mayor competidor entre 1849 y $1865^{13}$. Además, "las escenas empleadas originalmente coinciden con las elegidas por la KPM y Meissen"14, lo que puede llegar a dificultar las atribuciones cuando las piezas presentan únicamente un número. Ya a finales del siglo XIX descendió el interés en las litofanías y con ello su demanda, aunque Plaue nunca abandonó por completo la producción.

Siguiendo a la misma autora, "[e]n 1865 la Plauesche Porzellanmanufactur comenzó a utilizar su sello estándar, de modo que todas las litofanías marcadas PPM son posteriores a 1865. Con anterioridad, las placas se marcaban únicamente con números que se corresponden con la Preis-Courants [lista de precios]. Esto dificulta la datación de las piezas más antiguas. Parece que la marca PPM seguida de un número se utilizó por primera vez en 1880, y después de 1890, algunas litofanías de Plaue se marcaron sólo con números, sin marca alguna de tipo alfabético"15. El Museo del Romanticismo tiene identificadas siete placas de Plaue marcadas únicamente con un número (ver Anexo 1) y conserva cuarenta y ocho marcadas con las siglas PPM seguidas de un número o emplazadas sobre él (ver Anexo 2). Por tanto, según Margaret Carney, estas últimas se habrían realizado a partir de 1880, y más probablemente en esa década que en la siguiente. En todos los casos, el número de modelo (precedido del sello en las segundas) figura en el reverso, concretamente en el extremo inferior en las discoidales y en el ángulo inferior derecho en el caso de las que presentan formato rectangular (fig. 3). Sin perjuicio de todo ello, aunque el sello PPM permite una atribución inequívoca a Plaue, no hemos podido contrastar todos los modelos con la PreisCourants porque la publicada como Anexo E en el libro de Margaret Carney sólo llega hasta el número $755 \mathrm{y}$, como hemos señalado, la manufactura llegó a producir alrededor de dos mil

\footnotetext{
${ }^{12}$ Carney, 2008: 32.

${ }_{13}$ Carney, 2008: 32

${ }^{14}$ Carney, 2008: 33 .

${ }^{15}$ Carney, 2008: 33 .
} 


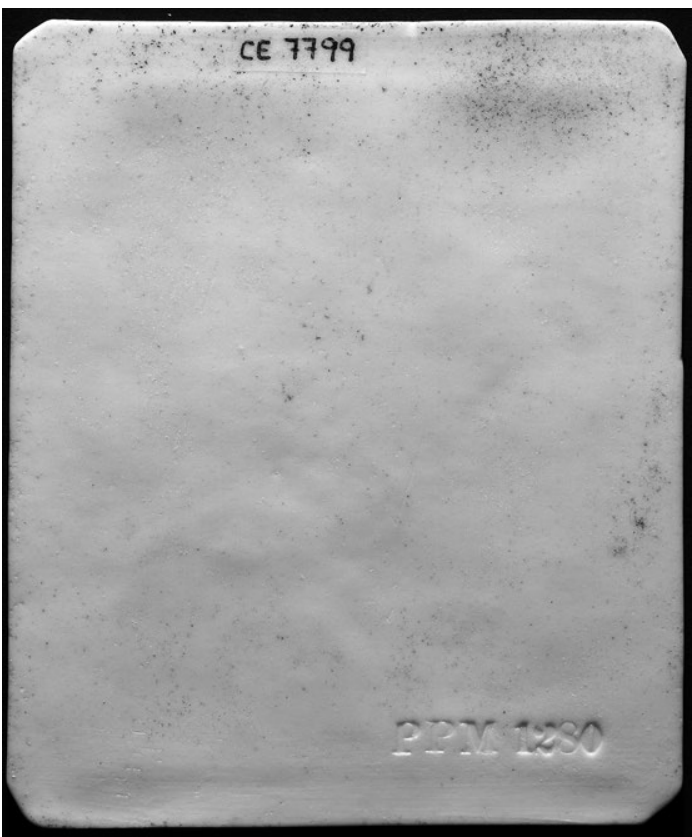

Fig. 3. Litofanía (reverso), Porzellanmanufactur Plaue, Hirsche am Wasser, Museo del Romanticismo, Madrid. inv. CE7799. Fotografía: Pablo Linés Viñuales.

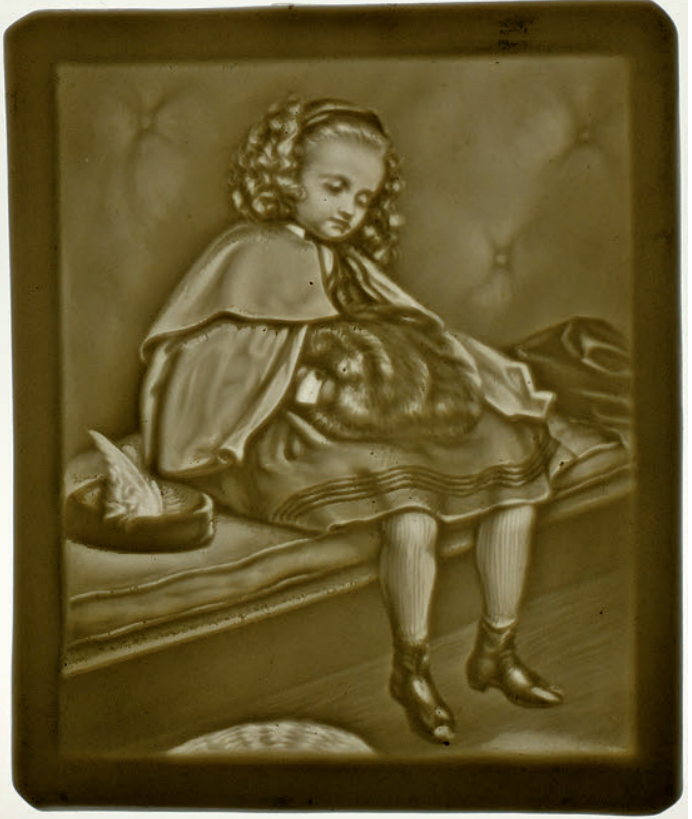

Fig. 4. Litofanía, Porzellanmanufactur Plaue (copia de J. E. Millais), My second sermon, Museo del Romanticismo, Madrid. inv. CE7671. Fotografía: Víctor Gascón González.

modelos diferentes. Por ese motivo, sólo hemos podido identificar correctamente los de veintitrés de las cuarenta y ocho placas mencionadas. No obstante, de las veinticinco restantes ha sido posible determinar algunos otros títulos porque o constan en el anverso o bien se conoce la fuente iconográfica original (fig. 4). Otros títulos mencionados en la tabla han sido facilitados por la propia manufactura de Plaue, a la que agradecemos haber puesto a nuestra disposición una lista de uso interno elaborada con base en sus propias investigaciones. No obstante, sería imprescindible contrastarla con las listas originales, sobre todo para los casos de algunas placas cuyas formas y/o escenas no se corresponden con los títulos asignados en aquélla a los números con los que éstas están marcadas ${ }^{16}$.

Entre estas cuarenta y ocho litofanías observamos ya algunas peculiaridades de estos objetos. Por lo que se refiere a sus formas, sólo dos de ellas son discoidales, siendo rectangulares las cuarenta y seis restantes. Las primeras solían disponerse en marcos con forma circular. Entre las segundas, cuarenta y tres son planas y tres semicilíndricas, en forma de teja. Estas últimas solían disponerse en pantallas de lámpara cilíndricas con estructura metálica panelada, de modo que cada panel albergaba una placa. Otra posibilidad era perforarlas en el borde inferior para incorporarlas al pie de una lámpara de mesa mediante un elemento metálico. En todo caso, parece que la diferente forma no conlleva necesariamente un número de modelo distinto puesto que el Museo del Romanticismo conserva tres placas marcadas con el número 881 y con la misma escena (inv. CE7675, CE7676 y CE7677), y otras tres con el número 849 y tema idéntico (inv. CE7765, CE7766 y CE7767), y en

16 Para aquellas litofanías cuyos títulos originales nos son desconocidos por el momento, hemos hecho constar en las tablas de los Anexos 2 y 3, entre corchetes, una breve referencia descriptiva a efectos meramente identificativos. 


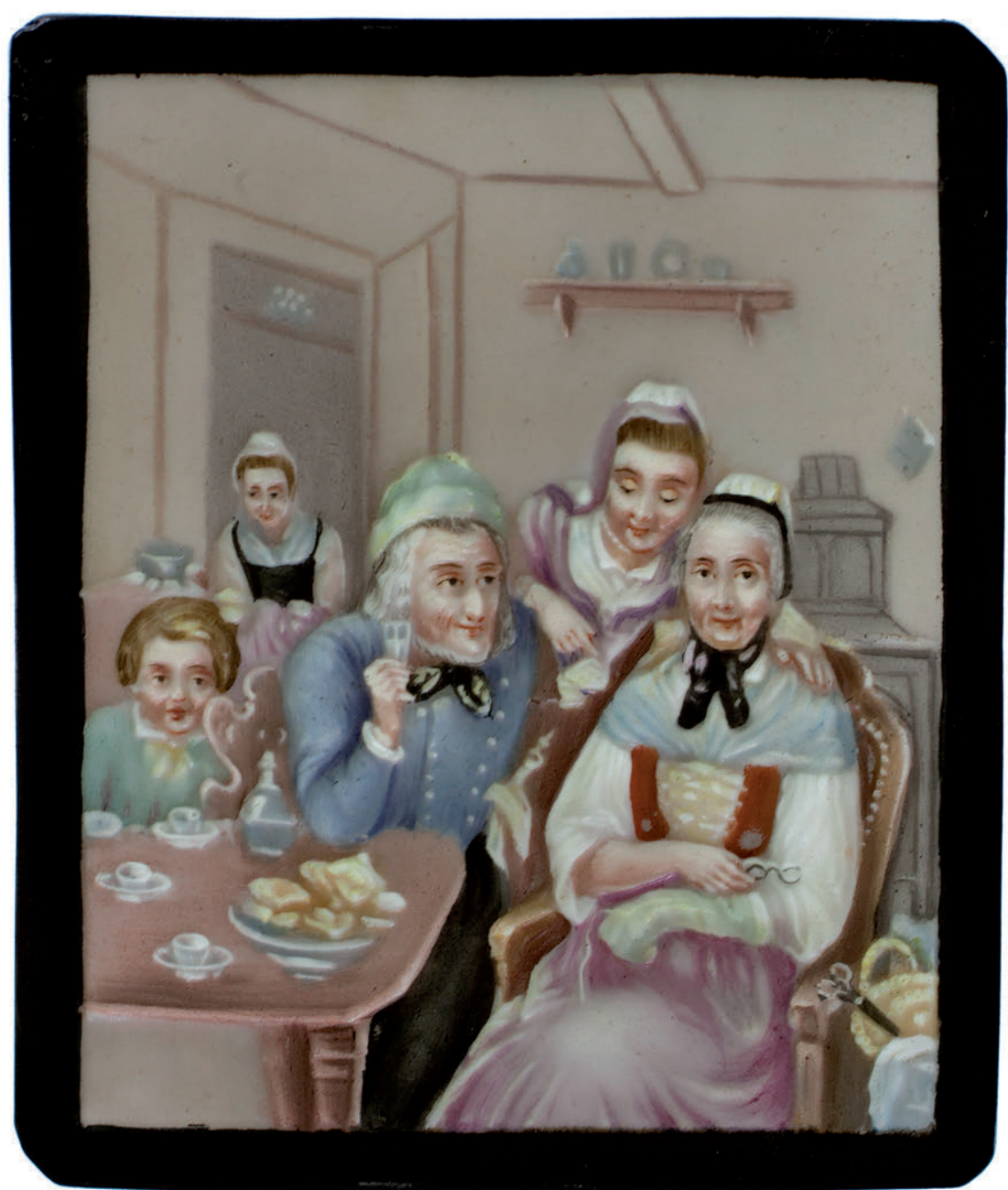

Fig. 5. Litofanía, Porzellanmanufactur Plaue, Das

Familienfest, Museo del Romanticismo, Madrid. inv. CE7749.

Fotografía: Víctor Gascón González.

ambos grupos dos de ellas son planas y una semicilíndrica. Sin embargo, esta circunstancia parece darse sólo cuando las litofanías comparadas presentan el mismo tamaño.

Otro distintivo de estos objetos de biscuit es el hecho de buscar el efecto de grisalla o claroscuro aludido al principio de estas páginas. No obstante, encontramos algunos ejemplares coloreados (fig. 5), los cuales eran sometidos a otra cocción, a menor temperatura, para fijar los pigmentos. Siguiendo a María del Pilar Arriola, "la mayor parte de las veces se coloreaban para disimular las imperfecciones que tuvieran, pero otras veces se fabricaban así expresamente a fin de satisfacer gustos menos exigentes. Al principio los artistas se limitaban a colorear las litofanías a la acuarela hasta que un artista chescolovaco K. Phohl consiguió integrar el color en la pasta de porcelana"17. Por su parte, Margaret Carney asegura que Meissen fue la primera manufactura en crear litofanías coloreadas en 1834, aunque parece que la primera en exhibirlas fue la Königliche Porzellan Manufaktur, en la Gran Exposición de Londres de $1851^{18}$. Más recientemente, Andrew R. Cook ha corroborado el dato de

\footnotetext{
17 Arriola, 1977: 27.

${ }^{18}$ Carney, 2008: 25, 31, 71.
} 
que la manufactura de Meissen comenzó a producir litofanías pintadas a mano a partir de 1834, añadiendo que también la de Viena y la de Alexis du Tremblay figuran entre las primeras que las produjeron -concretamente a finales de la década de 1830-, mientras que la KPM parece que empezó a hacerlas hacia 1849. Asimismo, afirma que la mayoría de las litofanías coloreadas conservadas actualmente datan de finales del siglo XIX y proceden de la manufactura von Schierholz de Plaue, que las marcaba con alguno de sus sellos habituales, ya fuera PPM o P.R. (hoz), o con alguno de los números de tres o cuatro dígitos reflejados en las listas de precios de la fábrica ${ }^{19}$.

En este primer gran grupo de litofanías de la Porzellanmanufactur Plaue encontramos un ejemplar con una peculiaridad que nos permite enlazar con los otros dos grupos de placas de la misma manufactura que conserva el Museo del Romanticismo, y dar paso con ellos al tema de la comercialización o distribución de las litofanías de Plaue en otros países, utilizando marcas distintas de las empleadas en las destinadas al mercado alemán. Nos referimos a una pieza marcada "PPM 808" (inv. CE7708) cuya escena infantil aparece igualmente representada en otra placa de la colección (inv. CE7709) que, al margen de no estar coloreada como aquélla, presenta una marca que consiste en las siglas "PR" sobre una hoz acompañadas de un número que no ha podido identificarse porque está oculto por una pieza metálica que se halla pegada a la porcelana para su sujeción a un pie de lámpara. Adicionalmente, en el anverso consta "G. Cuspinera. 1897", inscripción que podría responder a un encargo realizado por un comerciante para venderlas bajo su propio nombre.

En este sentido, en 1896 Gabriel Cuspinera y Oller y los hermanos Jaume y Joan Olivella y Montaner rompieron la sociedad que habían creado para hacerse cargo de la famosa "Casa Bachs" en la calle Fernando, $\mathrm{n}^{\mathrm{o}} 37$ de Barcelona. El motivo fue la decisión de Cuspinera de hacerse cargo del por entonces conocido establecimiento que Pere Llibre tenía en el $\mathrm{n}^{\circ} 11$ de la misma calle. El negocio no abrió sus puertas hasta el 14 de marzo de 1896 y pasó a denominarse "Casa Cuspinera". Estaba sito en el número 1 de la calle Fernando y en la tienda se vendían "bronces, porcelana y otros objetos de lujo" 20 . Es muy posible que Gabriel Cuspinera encargase litofanías con su nombre a la manufactura de Plaue. Sea como fuere, el Museo del Romanticismo conserva tres (inv. CE7709, CE7751 y CE7783). En las dos primeras, que son semicilíndricas, consta además la fecha, 1897, es decir, un año después de la apertura del establecimiento (fig. 6). En la tercera, que es plana, consta "Barcelona" en lugar de la fecha. El Museu Frederic Marès (Barcelona) posee una igual a la CE7751 (inv. MFM S-14341) y también el Museu del Cinema (Gerona) ${ }^{21}$. Se sabe que más adelante, en 1901, Gabriel Cuspinera viajó a París y Berlín, donde hizo "importantes compras"22. Aunque no hemos podido profundizar en el tipo de artículos que adquirió en esos viajes, parece razonable considerar la posibilidad de que las litofanías figurasen entre ellos. En este sentido, no hay que olvidar que en las postrimerías del siglo XIX Plaue abrió muestrarios en las dos ciudades mencionadas ${ }^{23}$.

Por lo que respecta en particular a la marca PR (hoz), el Museo del Romanticismo conserva cuarenta y seis placas que la contienen (ver Anexo 3). En 1995, Régine de Plival de Guillebon consideró que podría haberse utilizado en una manufactura de Montreuil-sous-Bois ${ }^{24}$. Trece años después, Margaret Carney sugiere la hipótesis de que exista una relación directa entre las piezas que la llevan y las marcadas PPM. Sostiene que las primeras fueron fabricadas entre 1899 y la Primera Guerra Mundial: "En 1899 murió Arthur von Schierholz y su empresa se convirtió en una sociedad limitada, uno de cuyos directivos estaba afiliado con un productor de porcelana que usaba

\footnotetext{
${ }^{19}$ Cook, 2014: 20-21.

20 “Crónica local”. En La Dinastía, Barcelona, 15-03-1896: 2.

${ }^{21}$ Frutos, 1996: 41; Riego/Piero/Frutos/Herrera, 2001: 105.

22 “Crónica local”. En La Dinastía, Barcelona, 14-02-1901: 2.
} 


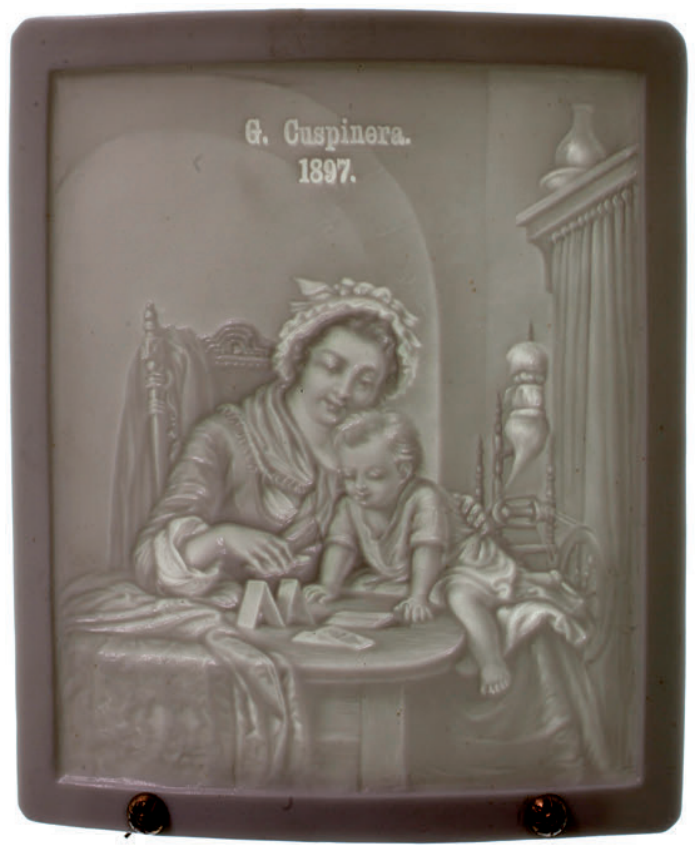

Fig. 6. Litofanía, Porzellanmanufactur Plaue, Mutter und Kind bauen Kartenhaus, Museo del Romanticismo, Madrid. inv. CE7751. Fotografía: Víctor Gascón González.

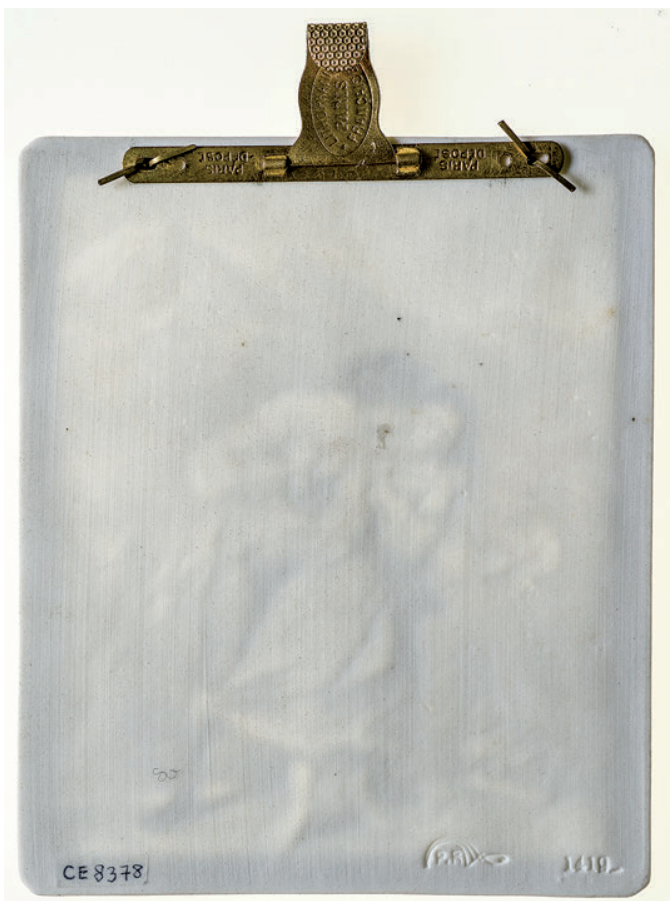

Fig. 7. Litofanía (reverso), Porzellanmanufactur Plaue, Liebespaar am Kornfeld,

Museo del Romanticismo, Madrid. inv. CE8378. Fotografía: José Luis Huelves Morata.

la marca P.R. (hoz) en el reverso. Igual que Meissen comercializó litofanías en Estados Unidos con "G.A.S.", es probable que Plaue eludiese las leyes de propiedad intelectual de Prusia produciendo y/o comercializando litofanías en Francia, marcadas con sellos "franceses" [Lithophanie Française y P.R. (hoz)], en lugar de PPM. No se han encontrado pruebas de lugar alguno en el que se fabricasen las litofanías marcadas Lithophanie Française o P.R. (hoz) en Francia (...)"25. Más recientemente, se ha dado por cierta esta hipótesis acerca de la relación directa entre las dos marcas. En este sentido, Andrew R. Cook afirma que la manufactura von Schierholz utilizó múltiples sellos de fábrica, incluido el de "Lithophanie Française" 26 , que de hecho figura inscrito en un óvalo en los sistemas de suspensión metálicos que presentan algunas placas (fig. 7), así como en la propia porcelana de algunas pantallas, en este caso rodeando una probeta inscrita en un círculo (Museo del Romanticismo, inv. CE7703). En todo caso, las litofanías con la marca P.R. (hoz) y un número presentan el tema decorativo que corresponde a ese número en la PreisCourants de Plaue. Adicionalmente, pese a que la citada institución no conserva ningún ejemplar, los hay que presentan las dos marcas en el reverso. Según Margaret Carney, en esos casos la marca PPM podría identificarse con el productor y la marca P.R. (hoz) podría corresponder al minorista

\footnotetext{
${ }^{23}$ Carney, 2008: 33.

${ }^{24}$ Plival de Guillebon, 1995: 322.

${ }^{25}$ Carney, 2008: 33.

${ }^{26}$ Cook, 2014: 20.
} 
o distribuidor en Francia ${ }^{27}$. La primera identificación es irrefutable. Y respecto a la segunda, en todo caso habría que adelantar la fecha de 1899 que sugiere para el comienzo del uso de la marca PR (hoz) puesto que, como hemos visto, en 1897 ya se utilizó en las litofanías que pudo encargar Gabriel Cuspinera ${ }^{28}$.

Adicionalmente, algunas placas con la marca PR (hoz), que la mayoría de las veces figura en el ángulo inferior derecho del reverso, incorporan una inscripción sobre ella que aparece incompleta en la mayor parte de las piezas del Museo del Romanticismo que la llevan. Se trata en particular de las letras " $\mathrm{M}^{\mathrm{QUE}} \mathrm{D}^{\mathrm{EE}}$ " $\mathrm{y}$, aunque es un dato que por el momento no ha sido posible contrastar, es muy probable que correspondan a la abreviatura de "MARQUE DÉPOSÉE", expresión similar a la de "PARIS DEPÓSÉ" que figura en las aplicaciones metálicas que conservan algunas de estas litofanías y que formaban parte de su sistema de montaje o suspensión.

Otras tres placas de este grupo de la colección del Museo del Romanticismo presentan además una "P" en el ángulo inferior izquierdo del reverso. Desconocemos el significado de esta letra, que podría referirse a la procedencia o tal vez corresponder a una marca de artífice, ya que en muchos casos se les pagaba por unidades realizadas y cada uno de ellos tenía asignado un símbolo o una letra distintiva.

Por otra parte, es interesante observar que más de la mitad de las placas marcadas P.R. (hoz) que conserva el Museo del Romanticismo presentan dos orificios en el borde superior para su probable suspensión con cadenas en las ventanas, aunque existen otras con uno o dos orificios en el extremo inferior. También las hay sin perforar, que posiblemente se exhibían en marcos o lámparas. En todo caso, en el Museo del Romanticismo se conservan los sistemas de suspensión o sujeción de muy pocos ejemplares.

La mayor parte de las litofanías marcadas P.R. (hoz) que se conservan en el Museo del Romanticismo tienen forma rectangular, rondando su dimensión máxima los $13 \mathrm{~cm}$. Por eso llaman especialmente la atención dos placas de gran tamaño que, a mayor abundamiento, poseen la particularidad de representar escenas religiosas frente a las costumbristas, amorosas, infantiles y familiares o incluso literarias que contienen las demás de este grupo. Nos referimos a las litofanías con números de inventario CE7811 (29,5 x 23,4 cm.) y CE7815 (25 x 21,2 cm.), que tienen asignados los números de modelo 1191 y 1270 , respectivamente, si bien, a juzgar por la lista interna a la que hemos tenido acceso, por el momento la manufactura no parece tener identificada la correspondencia de estos números con ningún tema en particular. Se trata en todo caso de dos versiones del descanso en la huida a Egipto, hacia donde la Sagrada Familia huyó para poner al Niño a salvo de la persecución de Herodes. Resta por tanto conocer la autoría de las fuentes iconográficas originales, dato que rara vez recogen las listas de precios de las distintas manufacturas.

Siguiendo con la de Plaue, debemos detenernos por último en otra pequeña litofanía de la colección objeto de estudio, que nos permite hablar de un nuevo aspecto de la producción en estas fábricas. Nos referimos a las placas miniatura que se realizaban para las casas de muñecas victorianas como réplicas exactas de las versiones en tamaño estándar, y que habitualmente contienen escenas infantiles, siendo frecuente representar a niños con sus mascotas. Tenían además la misma funcionalidad que aquéllas, pues también se acompañaban de los accesorios necesarios para iluminarlas. La del Museo del Romanticismo (inv. CE7683) conserva precisamente su marco (inv. CE7682), que incorpora en la parte posterior el lugar correspondiente para la vela, y que es igual al que acompaña a otra litofanía en miniatura, también de temática infantil, que conserva el Museo Municipal de

27 Carney, 2008: 33

28 De reciente aparición es el libro de KH. W. Steckelings, Leuchtender Stein: Die Geschichte der Lithophanie vom 18. bis ins 20. Jahrhundert (Ed. Hetjens-Museum, Deutsches Keramikmuseum, Düsseldorf, 2014), al que cuando se escriben estas páginas aún no hemos tenido acceso. Quede aquí al menos hecha indiciariamente la referencia, pues es probable que esta obra arroje mayor luz sobre éste y otros aspectos relacionados con las litofanías. 
Nürnberg (inv. GS9.417). Se desconoce la procedencia de ambas aunque esta última institución considera probable que la que conserva fuese realizada en la manufactura de von Shierholz, lo mismo que pensamos nosotros con respecto a la del Museo del Romanticismo, en cuya colección hay otra placa de tamaño estándar con la misma escena cuya producción en Plaue es incuestionable. No obstante, al no presentar aquélla ninguna marca, no podemos afirmar tal procedencia. No hay que olvidar, por otra parte, que las manufacturas se copiaban los modelos entre ellas.

\section{Meissen Manufaktur}

La Meissen Manufaktur fue una de las más famosas manufacturas europeas de porcelana de la época, y una de las de mayor renombre en lo que se refiere particularmente a la producción de litofanías. Fundada en 1710 por Augusto II el Fuerte (1670-1733), figura entre las primeras que comenzaron a producir estos objetos. A finales de 1828, el rey Antonio I de Sajonia expresó su deseo de que se fabricasen litofanías en la Real Manufactura y de que superasen además la calidad de las realizadas en Francia, de donde procedían varios modelos de muestra que se habían adquirido en la feria de Pascua de Leipzig. Al año siguiente, en la feria de otoño se vendieron 400 litofanías de Meissen, una cifra muy considerable teniendo en cuenta que en Prusia existían unas elevadas tasas a la importación de estos objetos con el fin de proteger a la Königliche Porzellan Manufaktur de Berlín, con la que de hecho Meissen tuvo una feroz competencia. Precisamente, la alta calidad de las litofanías de Berlín, por la que estos objetos llegaron a denominarse "transparencias de Berlín" 29 , fue un estímulo para que Meissen mejorase la de las suyas. De este modo, a mediados del siglo XIX logró obtener una pasta más blanca y dejar atrás el característico tono amarillento de las primeras litofanías que produjo.

A juzgar por la lista de precios de la manufactura ${ }^{30}$, la variedad de litofanías que produjo Meissen en el siglo XIX es ciertamente notable y, sin embargo, figuran entre los ejemplares más escasos en las colecciones públicas y privadas, siendo las más buscadas por los coleccionistas en todo el mundo $^{31}$. En este sentido, es preciso señalar que tienen unas dimensiones considerables y, como hemos indicado anteriormente, cuanto mayor era el tamaño más difícil era lograr una cocción satisfactoria. Esto explica que sean piezas más exclusivas y excepcionales y que sea escasa la salida al mercado de piezas de estas características. Recordemos que la colección del Museo del Romanticismo procede en un $95 \%$ de un particular, Antonio Guisado, que se afanó en completar la que compró a los herederos de Pedro Martínez Garcimartín, quien a su vez había dedicado cuarenta años de su vida a reunirlas ${ }^{32}$. Como es habitual en todas las colecciones, dentro de ella son mucho más numerosas las de pequeño tamaño, cuya dimensión mayor no alcanza los 17 centímetros en ningún caso, siendo de hecho muchas las que están en torno a los 9 centímetros. Por eso su proceso de realización era más fácil, además de producirse en mayores cantidades para su consumo nacional y para su exportación a otros países, especialmente a Estados Unidos y al Reino Unido. Ya hemos visto que las litofanías de Plaue son las más numerosas dentro de la colección del Museo y que son generalmente de pequeño formato. Sin embargo, tiene únicamente ocho litofanías de Meissen, siete procedentes de la colección Guisado y una de reciente adquisición por el Estado español a un particular. Todas ellas presentan formato rectangular y, excepto en un caso, su dimensión mayor supera los veinticuatro centímetros.

\footnotetext{
${ }^{29}$ Museu Frederic Marès (2007): "Litofanías. Objetos decorativos en el siglo XIX". En: http://w110.bcn.cat/fitxers/icub/museumares/mfm.litofaniescast.312.pdf [30-01-2015].

${ }^{30}$ Carney, 2008: 205.

${ }^{31}$ Carney, 2008: 29.
} 


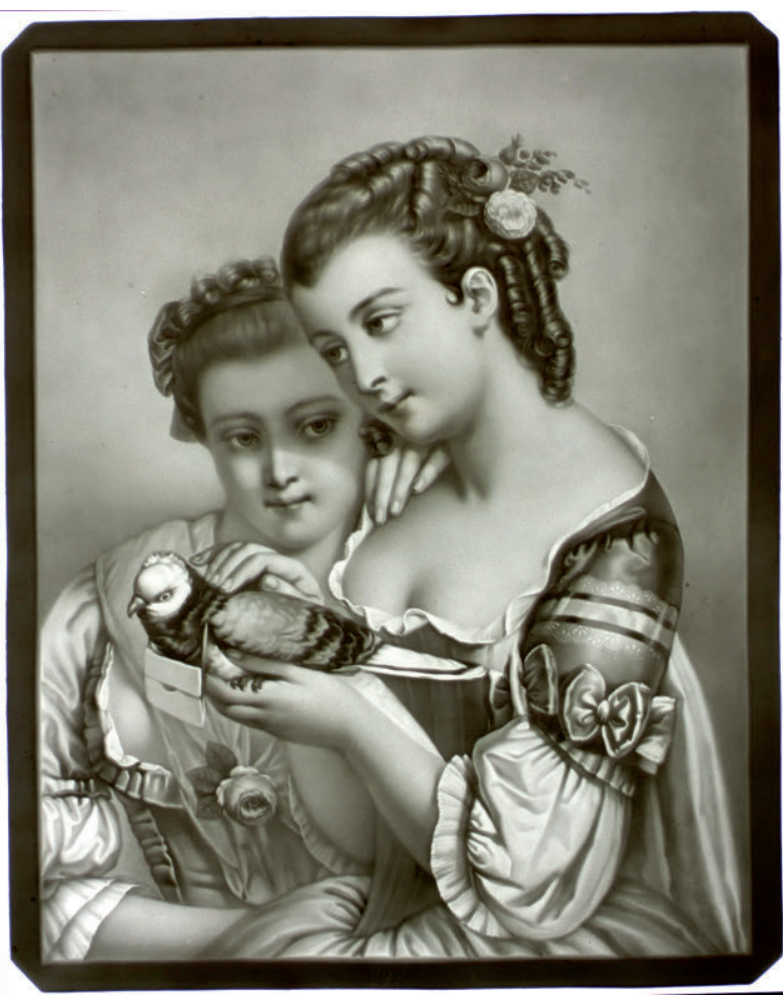

Fig. 8. Litofanía, Meissen Manufaktur, Zwei Mädchen mit Brieftaube, Museo del Romanticismo, Madrid. inv. CE7721. Fotografía: Víctor Gascón González.

Las litofanías realizadas en Meissen durante el siglo XIX suelen llevar una marca numérica incisa o estampada que corresponde al artífice, y siempre llevan otra, también numérica, estampada en el reverso y que corresponde al número de modelo tal y como figura en la lista de precios de la manufactura. Precisamente, la comparación de las placas con los números y los títulos o descripciones que constan en aquélla permite confirmar su atribución.

El Anexo 4 muestra los datos básicos de las ocho litofanías de Meissen de la colección del Museo del Romanticismo. Por lo que respecta en particular a su iconografía, hasta el momento hemos podido identificar únicamente la fuente de tres de los temas representados en ellas. Así, la placa con número de inventario CE7726, que en la lista de precios se titula Venus in Wolken (Venus en las nubes), reproduce la pintura El rapto de Psique, de Pierre Paul Prud'hon, y los números CE7816 y CE7817, que en la lista de referencia se titulan Madonna del Sixto (Madonna Sixtina) y Madonna del Sixto, klein, (Madonna Sixtina, pequeña), respectivamente, reproducen el famoso cuadro del mismo título pintado por Raffaello Sanzio. Por su parte, los números CE7721 y CE8446 (figs. 1 y 8), que según la lista de precios de Meissen se titulan Zwei Mädchen mit Hahn (Dos muchachas con gallo) y Zwei Mädchen mit Brieftaube (Dos muchachas con paloma mensajera), tienen una composición similar, complementándose incluso en la forma de presentación de las figuras pues, mientras en la 229 las muchachas están de perfil a la derecha, en la 227 lo están de perfil a la izquierda, formando una bellísima pareja que ejemplifica la excelente calidad que llegaron a alcanzar las litofanías de Meissen. Las escenas de estas dos placas pudieron obtenerse de estampas a partir de pinturas realizadas por Constant Joseph Brochart (Lille, 1816 Paris, 1894) o por algún artista de su círculo, puesto que guardan una gran semejanza con algunos de sus dibujos al pastel en lo que se refiere al tipo de retrato, la disposición de las figuras o su indumentaria. Sin embargo, no hemos podido confirmar este extremo por el momento.

\section{Königliche Porzellan Manufaktur (KPM)}

La Manufactura Real de Berlín fue fundada en 1751 a iniciativa del comerciante Wilhelm Caspar Wegely. En 1763, Federico II el Grande, rey de Prusia, se la adquirió a Johann Ernst Gotz-

\footnotetext{
32 Sáez-Angulo, 2008: 69.
} 


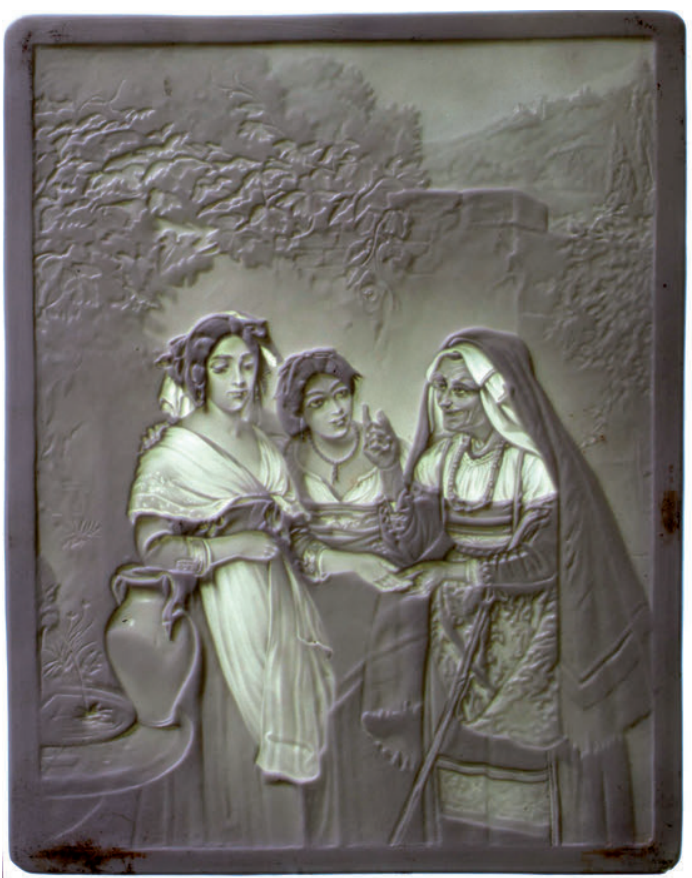

Fig. 9. Litofanía, Königliche Porzellan Manufaktur (copia de K. J. F. Cretius), Die Wahrsagerin, Museo del Romanticismo, Madrid. inv. CE7747. Fotografía: Víctor Gascón González.

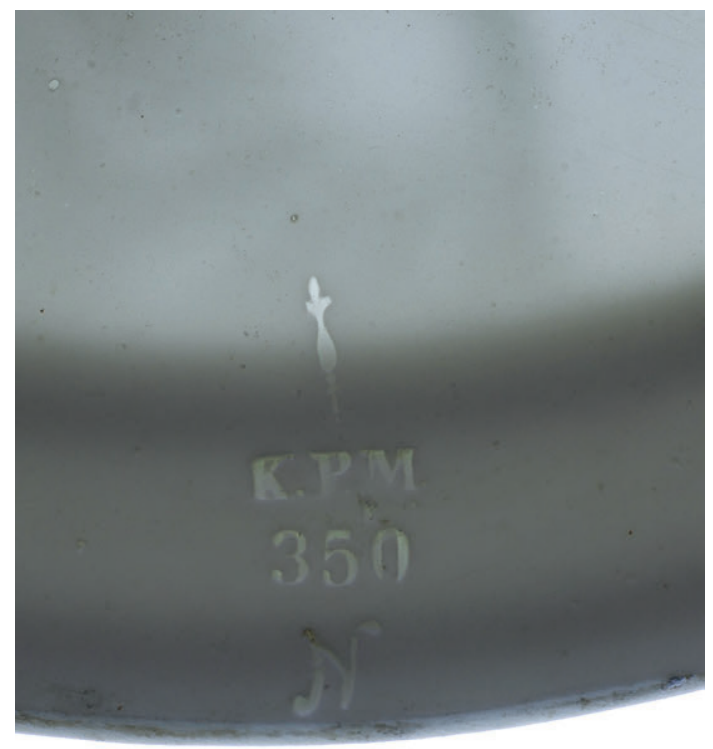

Fig. 10. Litofanía (detalle del reverso), Königliche Porzellan Manufaktur, Madonna, Museo del Romanticismo, Madrid, inv. CE7809, Fotografía: Víctor Gascón González.

kowsky, quien dos años antes había fijado la sede de la fábrica en la Leipziger Straße de Berlín, donde permaneció durante cien años. El rey asumió el control oficial de aquélla, dándole su nombre -Königliche Porzellan-Manufaktur Berlin (KPM)-y su emblema, el cetro real, marca que a partir de entonces figura en la base de todas las piezas.

Aunque la KPM se distinguió especialmente por sus vajillas de porcelana, también realizó litofanías, parcela de su actividad que ha sido estudiada en profundidad por Kirsten Rather-Pliquet. No obstante, hubo que esperar hasta 1828, manteniéndose la producción de estos objetos hasta 1865. Durante este período, produjo 580 modelos diferentes, siendo sobrepasada más tarde únicamente por la Plauesche Porzellanmanufactur. Adicionalmente, a ella se deben las litofanías más grandes que se hayan producido jamás ${ }^{33}$.

Como hemos adelantado, el Museo del Romanticismo conserva tan solo tres placas de esta procedencia. La primera de ellas (inv. CE7808) lleva el número 104, que se corresponde con el título "Madonna della Sedia", a partir del famoso cuadro de Raffaello Sanzio. La segunda (inv. CE7809) es la número 350, se identifica con el título "Madonna" y se la relaciona con la 104. Estas dos placas son discoidales y, según información facilitada por la KPM, se realizaron por primera vez en 1828 y 1846, respectivamente. La tercera es rectangular y representa una escena inspirada en una obra de Konstantin Johannes Franz Cretius que, a juzgar por la documentación empresarial de la manufactura, fue reproducida por vez primera en una litofanía en 1842, describiéndose el tema en la lista de precios como Die Wahrsagerin (La adivina) (inv. CE7747) (fig. 9). Precisamente, el

\footnotetext{
${ }^{33}$ Carney, 2008: 26-27.
} 
número 81 de la lista de precios de la manufactura de von Schierholz se corresponde con el mismo tema pero desconocemos si reproduce también la obra de Cretius. En todo caso, es una posibilidad que debemos considerar ya que, como hemos apuntado con anterioridad, las manufacturas se copiaban los modelos entre ellas.

Por lo que respecta en particular al sello, en las tres piezas consiste en el símbolo del cetro real sobre las siglas KPM, que a su vez figuran sobre el número de modelo y éste sobre la letra "N" (fig. 10). Atendiendo a la tabla de marcas que la propia manufactura tiene publicada en su página $\mathrm{web}^{34}$, la del cetro real sobre las siglas fue utilizada a partir de 1825 aproximadamente. Según Margaret Carney, fue más o menos desde 1836 cuando empezó a utilizarse con frecuencia para las litofanías, cuya producción había comenzado varios años antes, en $1828^{35}$. Por su parte, el número que figura debajo de las siglas se corresponde con la escena representada, pues también en este caso, como hemos visto, cada motivo decorativo tenía asignado un número en la lista de precios. Finalmente, la «N» que figura bajo dicho número podría ser una marca del artífice, teniendo en cuenta que se les pagaba en función del número de placas realizadas. Por esta hipótesis se inclina preferentemente Margaret Carney: "De la comparación de las placas en el Blair Museum y en otras colecciones cabe deducir que la letra no alude a la inicial del artista (grabador en cera), las dimensiones de la placa o el precio. Podría significar el año de producción. Incluso es aún más probable que la letra haga referencia a la persona que realizó la litofanía a partir del molde. (...) [L]a persona era pagada por pieza realizada (...) y podían contar su trabajo completo al final del día" ${ }^{36}$. Adicionalmente, tras la cocción, las piezas que sobrevivían al horno se podían contar, y el código alfabético permitía saber cuáles se rompían con mayor frecuencia y tener un mayor control sobre la calidad de la producción ${ }^{37}$. De todos modos, se trata únicamente de una suposición que debemos contrastar, ya que resulta curioso que las tres litofanías de la KPM que conserva el Museo del Romanticismo presenten la misma letra y que, además, en dos de ellas esté estampada y en la tercera incisa.

\section{Nymphenburg Porzellan Manufaktur}

Otra manufactura alemana que produjo litofanías fue la Nymphenburg Porzellan Manufaktur de Munich, que todavía hoy las fabrica conforme a las técnicas artesanales tradicionales. Aunque fue fundada en 1747 gracias al príncipe elector Maximilian III Joseph (1727-1777), comenzó a realizar estos refinados objetos bajo el reinado de Luis I (1825-1848) y se tiene noticia de que figuraron en la Exposición Industrial de Munich de 1834. Entre los artistas que las produjeron figuran Anton Hüttlinger y Otto Wustlich, que trabajaron en la manufactura desde 1839 hasta 1856 y desde 1854 hasta 1868, respectivamente, a las órdenes del que entonces era su responsable, el pintor afincado en Munich Eugen Napoleon Neureuther (1806-1882).

El Museo del Romanticismo conserva únicamente dos placas de esta procedencia y no sorprende que no haya más puesto que, como ha señalado Margaret Carney, las litofanías del siglo XIX producidas en Nymphenburg podrían considerarse como muy $\operatorname{raras}^{38}$. Una de ellas (inv. CE7813) es una Mater Dolorosa aunque por el momento no hemos podido identificar la fuente iconográfica, y la otra (inv. CE7814) reproduce la pintura de Guido Reni Cristo Coronato di spine (fig. 11). Precisamente, la procedencia de la segunda ha sido confirmada por la propia manufactura, que conserva el molde original. Pero además, ambas presentan la misma marca en el reverso, una "G". Esto nos per-

\footnotetext{
${ }^{34}$ https://de-de.kpm-berlin.com/fileadmin/user_upload/docs/handwerkskunst/Markentafel.pdf [30-01-2015].

${ }^{35}$ Carney, 2008: 24.

${ }^{36}$ Carney, 2008: 26.

37 Carney, 2008: 26.

${ }^{38}$ Carney, 2008: 24.
} 


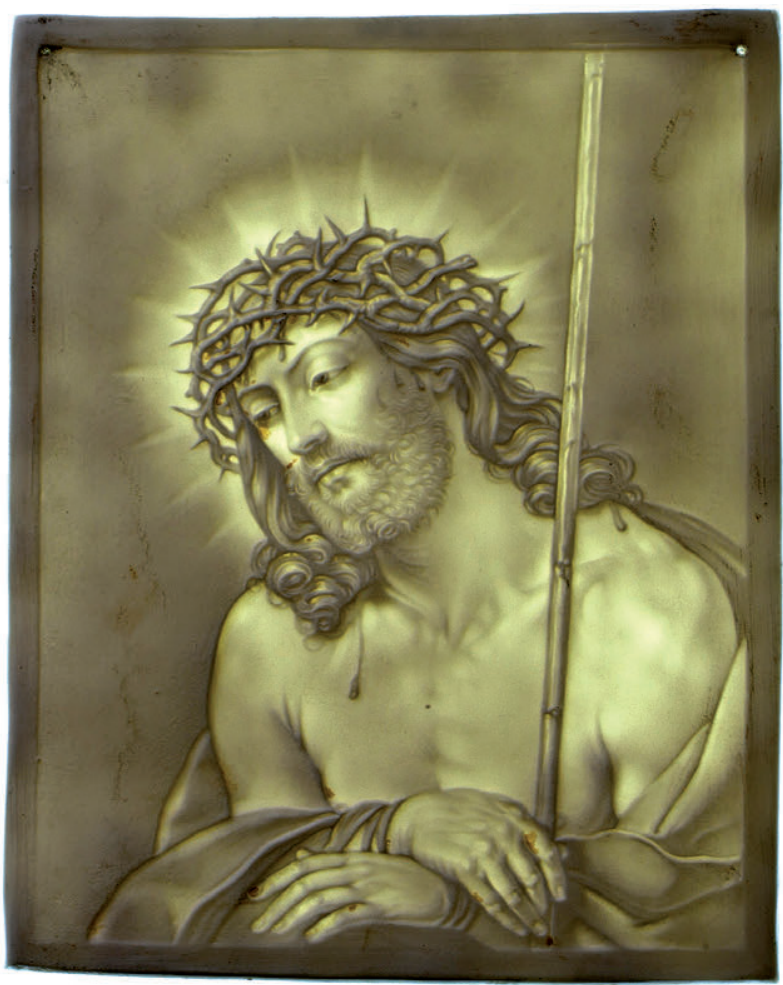

Fig. 11. Litofanía, Nymphenburg Porzellan Manufaktur (copia de G. Reni), Cristo coronato di spine, Museo del Romanticismo, Madrid. inv. CE7814. Fotografía: Víctor Gascón González.

mite enlazar con el singular sistema de marcaje de esta fábrica, del que aún hoy quedan por despejar algunas incógnitas. En este sentido, la última referencia sobre litofanías de Nymphenburg del siglo XIX la encontramos en la lista de precios de 1870, a la que hemos tenido acceso por cortesía de la manufactura. Contiene una serie de iniciales a las que se asocian las formas de las placas y sus precios en kreutzer y en florines. La letra " $G$ " con la que están marcadas las dos placas del Museo del Romanticismo aparece por triplicado en la lista y las tres veces tiene asociado el mismo precio en kreutzer. Según información facilitada por Nymphenburg, no parece que las letras hayan de relacionarse ni con los artífices ni con el sistema de almacenaje de las litofanías en la fábrica, información que, de hecho, no suele aparecer en una lista de precios. En cambio, hemos visto que sí suelen constar en las de otras manufacturas alemanas de la época alusiones a los temas representados en las piezas. Pero tampoco parece que sea ese el caso, ya que las dos placas del Museo del Romanticismo tienen distinto tema y misma marca.

Las escenas religiosas como las de estas dos litofanías figuraban entre las más frecuentes junto a las mitológicas, perspectivas arquitectónicas de Munich, escenas alpinas y paisajes románticos. Adicionalmente, y en la misma línea que se hacía con las denominadas plate paintings (platos pintados) - que eran las producciones más distinguidas de Nymphenburg-, también en las litofanías se reprodujeron obras de los antiguos maestros pertenecientes a la colección regia, así como una serie de retratos de miembros de la familia real.

\section{Carl Heyroth \& Co.}

Se sabe muy poco sobre la manufactura fundada por Carl Heyroth (1797-1881) ${ }^{39}$, que al parecer empezó a dedicarse a la porcelana hacia 1830 en Magdeburg. Posteriormente, cambió de ubicación a Sudenburg, donde compró una parcela en 1836 y construyó una nueva fábrica. Allí produjo litofanías desde 1844 hasta el cierre de aquélla en 1853, y las marcaba con dos distintivos alfabéticos alternativos, "HPM" o "HPF", tradicionalmente atribuidos a la Hennebergsche Porzellan Manufaktur (Gotha, Turingia), como ha sugerido Margaret Carney ${ }^{40}$. Desde el punto de vista iconográfico, era

\footnotetext{
39 De nuevo nos remitimos al libro anteriormente citado de KH. W. Steckelings, de reciente publicación.

40 Carney, 2008: 22.
} 
habitual que tomasen los temas de pinturas de artistas alemanes de la época como Wilhelm Rudolph Jordan (1810-1887), Johann Georg Meyer (1813-1880), Hermann Werner (1816-1905), Jacob Becker (1810-1872) o Johann Peter Hasenclever (1810-1853).

El Museo del Romanticismo conserva tres placas con la marca "HPM" en el reverso sobre otra numérica que, a su vez, está encima de una letra suelta cuyo significado ignoramos por el momento. Tampoco ha sido posible identificar las fuentes iconográficas de las escenas familiares e infantiles que las decoran, en todo caso muy del estilo de la obra de los artistas mencionados (fig. 12).

\section{Avramov}

El Museo del Romanticismo conserva una litofanía realizada ya en el siglo XX por el artista de origen búlgaro Chris Avramov. Su padre y su abuelo fueron renombrados escultores que le enseñaron las técnicas de bajorrelieve en plata y en porcelana. A los veintidós años dejó su país natal y se fue a vivir a Israel donde

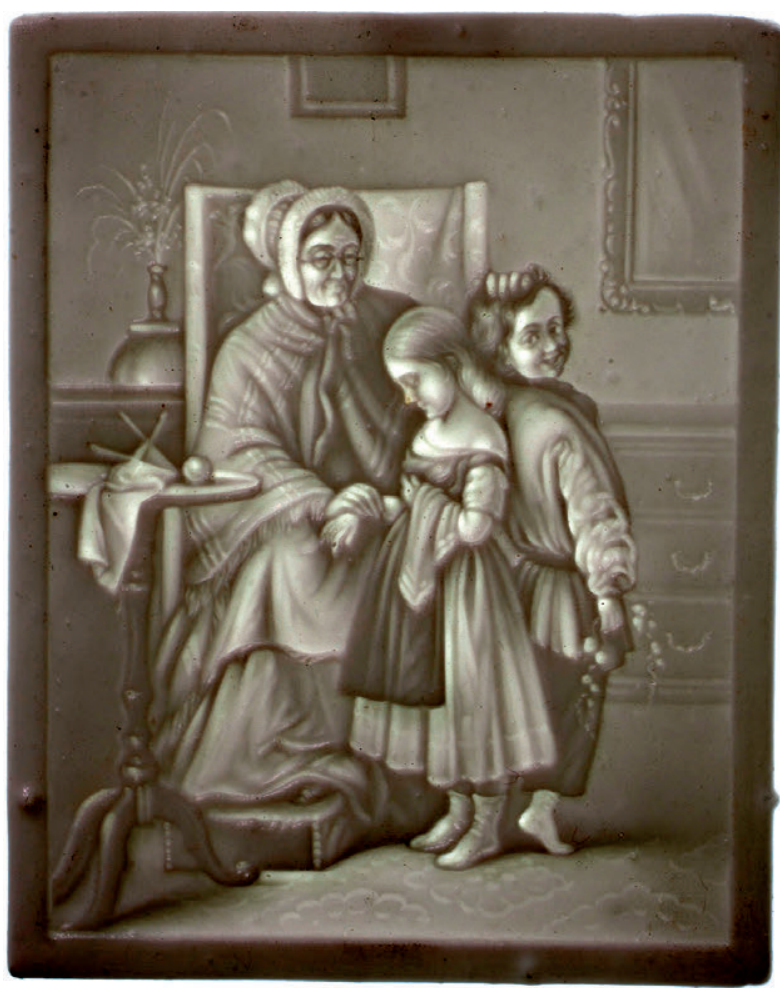

Fig. 12. Litofanía, Carl Heyroth \& Co., Museo del Romanticismo, Madrid. inv. CE7740. Fotografía: Víctor Gascón González. permaneció durante doce años. Posteriormente, se trasladó a España, donde conoció a Antonio Guisado. En esta ocasión, nos interesa su actividad en el ámbito de la porcelana. Sabemos que en febrero de 1978 visitó junto al citado coleccionista el Blair Museum of Lithophanes de Toledo (Ohio) y que se ofreció a hacer litofanías para los miembros de la institución a partir de sus propios moldes, marcándolas con su nombre y con la fecha para distinguirlas de las decimonónicas ${ }^{41}$. Previamente, había desarrollado esta técnica practicando con las litofanías del señor Guisado, como ejemplifica la que conserva el Museo del Romanticismo (inv. CE7759), que sólo está marcada con el nombre "c. avramov" en el extremo inferior del reverso y que reproduce una de las placas realizadas en la manufactura de Carl Heyrouth (inv. CE7758), de la que sacó primero el molde correspondiente. Por lo tanto, necesariamente el ejemplar resultante es de menor tamaño y también de menor calidad.

Hasta aquí esta primera aproximación a la colección de litofanías del Museo del Romanticismo que, como hemos visto, constituye una excepcional muestra de la producción decimonónica de estos objetos, tan impregnados del espíritu romántico. Ulteriores estudios permitirán seguir profundizando en la identificación y catalogación de estas delicadas piezas que, gracias a la devoción que suscitaron -y continúan suscitando- entre algunos coleccionistas, han llegado hasta nosotros para que podamos sumergirnos en el siglo XIX al contemplar en ellas las casas de las gentes, sus costumbres, su indumentaria, sus paisajes, sus sueños y sus leyendas.

\footnotetext{
${ }^{41}$ Blair, 1978: 2.
} 


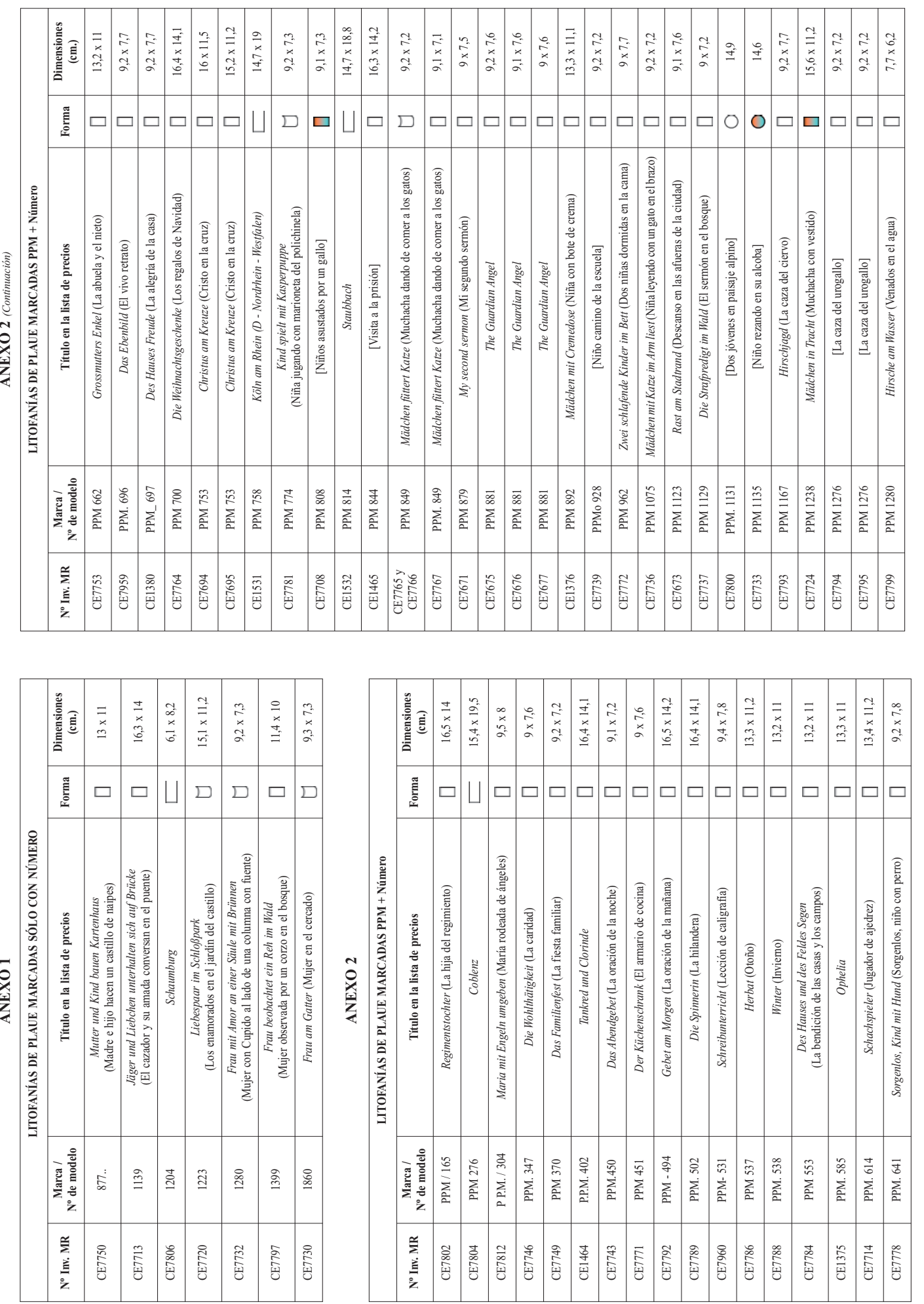




\begin{tabular}{|c|c|c|c|c|c|c|c|c|c|c|c|c|c|c|c|c|c|c|c|c|c|c|}
\hline \multirow{5}{*}{ 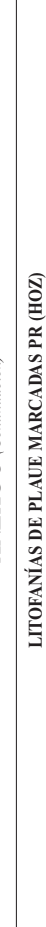 } & 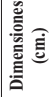 & 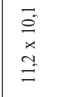 & $\begin{array}{l}\bar{x} \\
= \\
=\end{array}$ & $\mid \begin{array}{c}\infty \\
\infty \\
\stackrel{\infty}{\leftrightarrows} \\
=\end{array}$ & $\stackrel{\vec{\infty}}{\stackrel{\phi^{+}}{=}}$ & 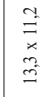 & $\begin{array}{l}\bar{y} \\
\tilde{x} \\
\cong\end{array}$ & 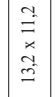 & 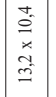 & 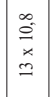 & 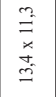 & 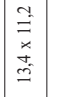 & $\begin{array}{l}\overline{\bar{x}} \\
\hat{x} \\
\underline{\underline{z}}\end{array}$ & $\begin{array}{l}\stackrel{O}{x} \\
\stackrel{x}{I}\end{array}$ & 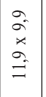 & $\begin{array}{l}\overline{\bar{x}} \\
\stackrel{x}{=}\end{array}$ & $\begin{array}{l}\stackrel{\circ}{\vec{\partial}} \\
\stackrel{x}{\underline{m}}\end{array}$ & 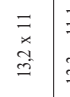 & 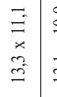 & $\frac{2}{3}$ & 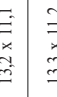 & \\
\hline & 嵒 & ㅁ & $\square$ & $\square$ & $\square$ & $\square$ & $\square$ & $\square$ & $\square$ & $\square$ & $\square$ & 마 & $\square$ & $\square$ & $\square$ & 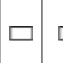 & ㅁ & ㅁ & $\square$ & $\square$ & ح & \\
\hline & 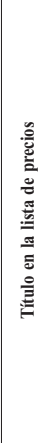 & 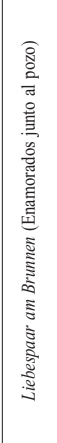 & 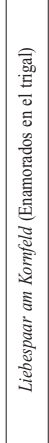 & 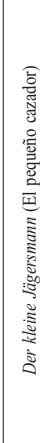 & 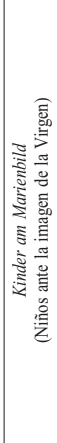 & 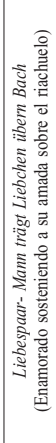 & 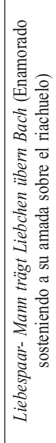 & 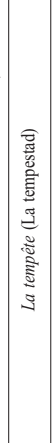 & 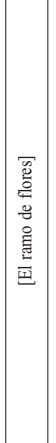 & 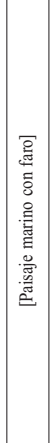 & 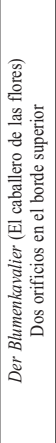 & 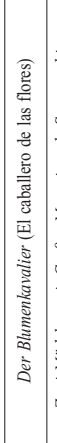 & 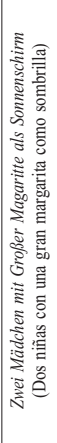 & 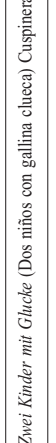 & 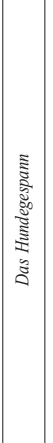 & 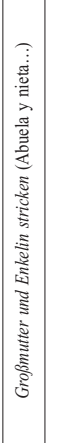 & 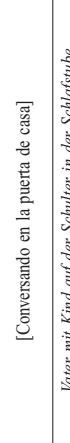 & 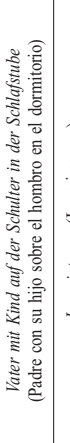 & 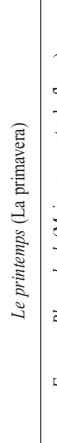 & 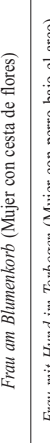 & 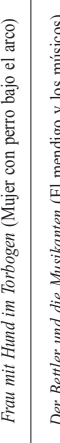 & \\
\hline & 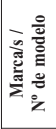 & 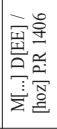 & 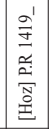 & 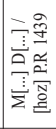 & 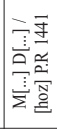 & 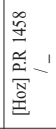 & 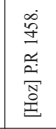 & 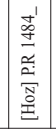 & 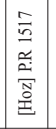 & 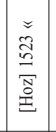 & 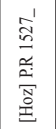 & 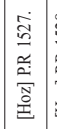 & 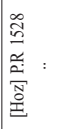 & 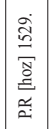 & 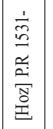 & 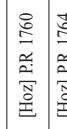 & 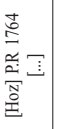 & 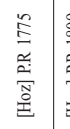 & 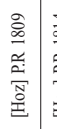 & 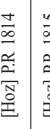 & 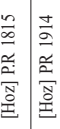 & \\
\hline & 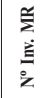 & 总 & 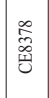 & \begin{tabular}{|l} 
里 \\
嘼
\end{tabular} & $\begin{array}{l}\text { 总 } \\
\text { 总 }\end{array}$ & 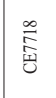 & 总 & $\begin{array}{l}\overline{\mathbf{E}} \\
\text { 要 }\end{array}$ & 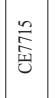 & \begin{tabular}{|l} 
总 \\
总
\end{tabular} & 产 & 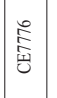 & 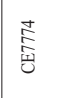 & $\begin{array}{l}\text { 总 } \\
\text { 严 }\end{array}$ & $\mid \begin{array}{l}8 \\
8 \\
19 \\
0\end{array}$ & 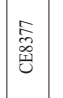 & 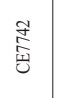 & $\begin{array}{l}\underset{F}{F} \\
\text { 恶 }\end{array}$ & 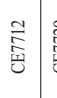 & & 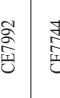 & \\
\hline
\end{tabular}

\begin{tabular}{|c|c|c|c|c|c|c|c|c|c|c|c|c|c|c|c|c|c|c|c|c|c|c|c|c|c|c|}
\hline \multirow{5}{*}{ 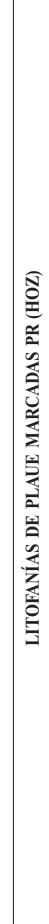 } & 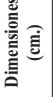 & 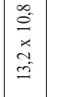 & 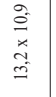 & $\begin{array}{l}\text { 嶽 } \\
\stackrel{x}{=}\end{array}$ & 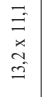 & 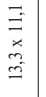 & 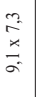 & 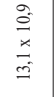 & $\begin{array}{l}\overline{\underline{x}} \\
\stackrel{x}{=}\end{array}$ & 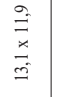 & $\begin{array}{l}\bar{x} \\
\bar{x} \\
=3\end{array}$ & $\begin{array}{ll}\overrightarrow{\bar{B}} \\
\underline{\underline{x}}\end{array}$ & 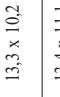 & 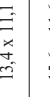 & 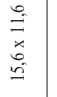 & 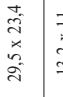 & $\begin{array}{l}\bar{y} \\
\underline{x} \\
\underline{z}\end{array}$ & 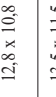 & 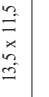 & 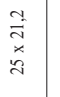 & 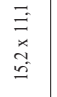 & 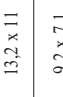 & 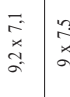 & $\begin{array}{l}2 \\
z \\
\vdots \\
\alpha \\
\alpha\end{array}$ & 离 & $\begin{array}{l}\stackrel{2}{\sigma} \\
\alpha \\
\stackrel{\alpha}{=}\end{array}$ \\
\hline & 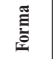 & $\square$ & ㅁ & $\square$ & $\square$ & $\square$ & $\square$ & $\square$ & $\square$ & $\square$ & $\square \square$ & $\square$ & $\triangle 0$ & $\nabla$ & $\square$ & $\square$ & $\square$ & $\square$ & $\square$ & ㅁ & ㅁ & $\square 2$ & $\square$ & $\square \quad 2$ & $\square$ & $D$ \\
\hline & 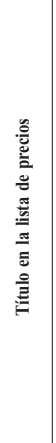 & 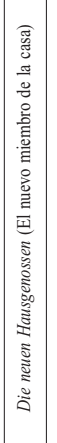 & 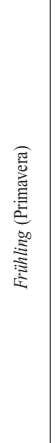 & 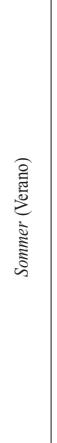 & 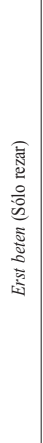 & 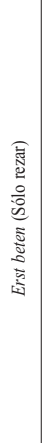 & 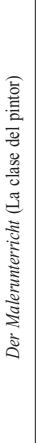 & 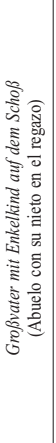 & 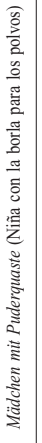 & 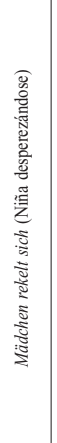 & 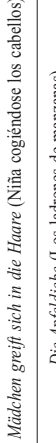 & 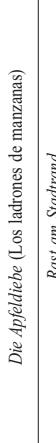 & 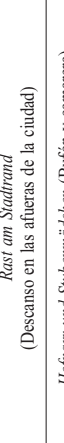 & 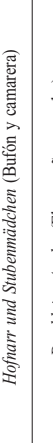 & 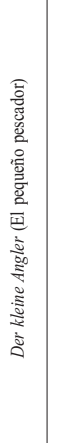 & & 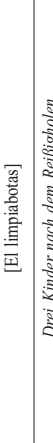 & 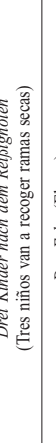 & 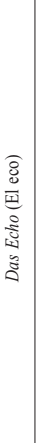 & 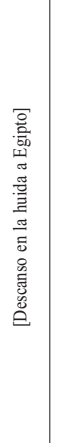 & 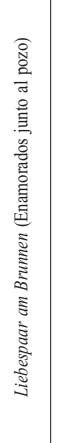 & 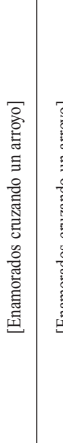 & 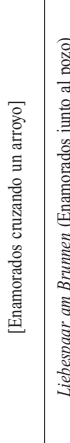 & 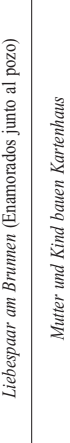 & 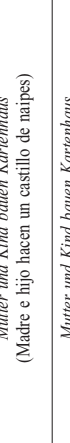 & 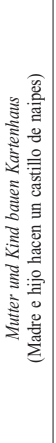 \\
\hline & 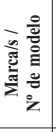 & 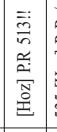 & 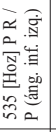 & 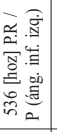 & 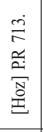 & 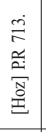 & 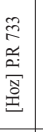 & 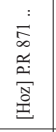 & 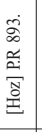 & 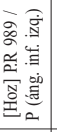 & 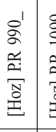 & 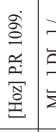 & 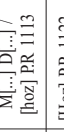 & 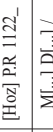 & 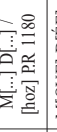 & 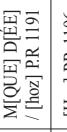 & 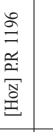 & 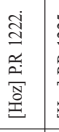 & 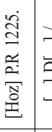 & 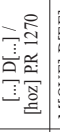 & 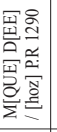 & 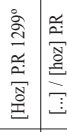 & 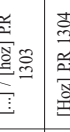 & 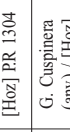 & 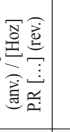 & 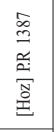 \\
\hline & 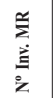 & 意 & 惫 & 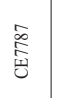 & 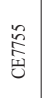 & 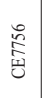 & है & 竧 & $\begin{array}{l}8 \\
\stackrel{8}{8} \\
\end{array}$ & ह气 & 总 & 兽 & 府 & 总 & 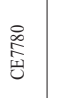 & $\begin{array}{l}\overline{\bar{o}} \\
\vec{U}\end{array}$ & 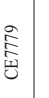 & 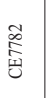 & 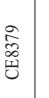 & 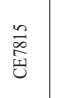 & 总 & 䓛 & हે & 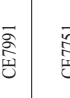 & 章 & 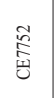 \\
\hline
\end{tabular}


ANEXO 4

\begin{tabular}{|c|c|c|c|c|}
\hline \multicolumn{5}{|c|}{ LITOFANÍAS DE LA MANUFACTURA REAL DE MEISSEN } \\
\hline $\begin{array}{l}\text { No Inv. }^{0} \text { MR } \\
\text { MR }\end{array}$ & Título en la lista de precios & $\begin{array}{l}\mathrm{N}^{0} \text { de modelo } \\
\text { (verso) }\end{array}$ & $\begin{array}{l}\text { Marca de artífice } \\
\text { (verso) }\end{array}$ & $\begin{array}{l}\text { Dimensiones } \\
\quad \text { (cm.) }\end{array}$ \\
\hline CE7721 & $\begin{array}{l}\text { Zwei Mädchen mit Brieftaube } \\
\text { (Dos muchachas con paloma mensajera) }\end{array}$ & $\begin{array}{l}227 \text { (centro del } \\
\text { extremo inferior) }\end{array}$ & $\begin{array}{l}74 \text { (ángulo inferior } \\
\text { izquierdo) }\end{array}$ & $24,4 \times 19,2$ \\
\hline CE7722 & Der Beduinenraub (El secuestrador beduino) & $\begin{array}{l}202 \text { (centro del } \\
\text { extremo inferior) }\end{array}$ & $\begin{array}{l}35 \text { (ángulo inferior } \\
\text { derecho) }\end{array}$ & $26,4 \times 21,6$ \\
\hline CE7726 & Venus in Wolken (Venus en las nubes) & $\begin{array}{l}35 \text { (ángulo } \\
\text { superior derecho) }\end{array}$ & $\begin{array}{l}61 \text { (ángulo superior } \\
\text { izquierdo) }\end{array}$ & $19,5 \times 15$ \\
\hline CE7728 & Mädchen am Spiegel (Muchacha ante el espejo) & $\begin{array}{l}116 \text { (centro del } \\
\text { extremo inferior) }\end{array}$ & $\begin{array}{l}59 \text { (ángulo inferior } \\
\text { derecho) }\end{array}$ & $24,3 \times 19$ \\
\hline CE7734 & Der Liebestraum (El sueño de amor) & $\begin{array}{l}201 \text { (centro del } \\
\text { extremo inferior) }\end{array}$ & $\begin{array}{l}59 \text { (ángulo inferior } \\
\text { derecho) }\end{array}$ & $25,8 \times 19,1$ \\
\hline CE7816 & Madonna del Sixto (Madona Sixtina) & $\begin{array}{l}83 \text { (centro del } \\
\text { extremo inferior) }\end{array}$ & $\begin{array}{l}50 \text { (ángulo inferior } \\
\text { derecho) }\end{array}$ & $28,4 \times 22,5$ \\
\hline CE7817 & Madonna del Sixto, klein (Madona Sixtina, pequeña) & $\begin{array}{l}94 \text { (ángulo inferior } \\
\text { derecho) }\end{array}$ & $\begin{array}{l}74 \text { (ángulo inferior } \\
\text { izquierdo) }\end{array}$ & $24,3 \times 19,2$ \\
\hline CE8446 & Zwei Mädchen mit Hahn (Dos muchachas con gallo) & $\begin{array}{l}229 \text { (centro del } \\
\text { extremo inferior) }\end{array}$ & $\begin{array}{l}50 \text { (ángulo inferior } \\
\text { derecho) }\end{array}$ & $25,2 \times 20,1$ \\
\hline
\end{tabular}

\section{BIBLIOGRAFÍA}

Arriola, María del Pilar (1977): "Un caso único en el mundo: La colección de litofanías de D. Antonio Guisado en El Escorial”. En Cisneros: una revista para Madrid y su provincia, 57, Madrid, pp. 25-29.

Blair, Laurel Gotshall (1978): Bulletin no. 13. Toledo (Ohio): Blair Museum of Lithophanes.

Carney, Margaret (2008): Lithophanes. Pennsylvania: Schiffer.

Cook, Andrew R. (2014): "Lithophanes: An Introduction to $19^{\text {th }}$ Century Porcelain 'Transparencies"'. En Antique Collecting, 48, 7, London, pp. 16-21.

Frutos, Francisco Javier (1996): La Fascinación de la mirada: los aparatos precinematográficos y sus posibilidades expresivas. Valladolid: Consejería de Educación y Cultura.

Guisado, Sonia (1991): Las litofanías de San Lorenzo de El Escorial. Madrid: SERSA.

Heugatter, Katherine (2010): "The lithophane: A Forgotten Nineteenth Century Art Form”. En Campbell House Courier, Winter, pp. 3 y 6.

Plival de Guillebon, Régine de (1995): Faïence et porcelaine de Paris, XVIIIe - XIXe siècles. Dijon: Editions Faton.

Rather-Pliquet, Kirsten (1993): Die Lithophanien der KPM Berlin (1828-1865): ein Beitrag zur Porzellangeschichte des 19. Jahrhunderts. Hamburg: Universitat.

Riego, Bernardo/Piero, Gian/Frutos, Francisco Javier/Herrera, Javier (2001): Memorias de la mirada: las imágenes como fenómeno cultural en la España contemporánea. Santander: Fundación Marcelino Botín, 2001.

Sáez-Angulo, Julia (2008): "Litofanías: Ornamentos translúcidos". En Galería Antiqvaria, 276, Madrid, pp. 68-70.

Steckelings, Karl Heinz W. (2014): Leuchtender Stein: Die Geschichte der Lithophanie vom 18. bis ins 20. Jahrhundert. Düsseldorf: Hetjens-Museum, Deutsches Keramikmuseum.

Fecha de recepción: 11-II-2015

Fecha de aceptación: 17-VI-2015 